\title{
COLD SHOCK OF BACTERIA
}

\section{MAGNESIUM-MEDIATED RECOVERY FROM COLD SHOCK AND EXISTENCE OF TWO CRITICAL TEMPERATURE ZONES IN VARIOUS BACTERIA}

\author{
MIKIO SATO AND HAJIME TAKAHASHI \\ Department of Agricultural Chemistry, Faculty of Agriculture, \\ Tohoku University, Sendai
}

(Received December 6, 1968)

\begin{abstract}
Escherichia coli, Pseudomonas fluorescens, and Bacillus subtilis cells, harvested at the logarithmic phase of growth, were susceptible to cold shock as judged by their loss in viabilities. Viabilities of cold shocked cells increased rapidly upon incubation at $30^{\circ}$ with suitable additives. Among the effective agents, magnesium ion was the most important, because no appreciable recovery in viability was observed in the absence of magnesium. When the cold shocked $E$. coli cells were incubated at $30^{\circ}$ with $5 \times 10^{-3} \mathrm{M}$ of magnesium acetate for 10 to $20 \mathrm{~min}$, the viability of shocked cells became equal to that of unshocked cells. The addition of 2,4-dinitrophenol to such systems inhibited the magnesium-mediated recovery almost completely. When NAD or ATP plus nicotinamide was further added to the reaction mixture, the inhibition by 2, 4-dinitrophenol was released. This result suggests that NAD, possibly as an energy source, is involved in the recovery process.

An increase in permeability of cold shocked $E$. coli cells was demonstrated with the aid of 8-anilino-1-naphthalenesulfonate. The stimulatory effect of NAD or ATP added to the reaction mixture on the recovery from the cold shock could be explained by this permeability increase.

The presence of two critical temperature zones in the cold shock was confirmed with both B. subtilis and Ps. fluorescens. When the initial temperature of the cell suspension before the cold shock was lowered by $5^{\circ}$, both temperature zones moved to lower temperatures approximately by $3-5^{\circ}$.
\end{abstract}

In a preceding paper of this series (1), we have shown that Escherichia coli cells, harvested at the late logarithmic phase of growth, are susceptible to a cold shock. The cells lose their viability to a great extent upon rapid chilling. The presence of magnesium, calcium, or manganese ion at a concentration of $5 \times 10^{-3} \mathrm{M}$ in the chilled buffer to which the cells are suspended markedly protects the cells from the effect of cold shock. Bivalent cation, magnesium or calcium, when added immediately after the chilling, bring about a marked recovery in viability. Under optimal conditions, that is, a brief 
exposure of $10^{-1} \mathrm{M}$ of magnesium acetate or sulfate to the shocked cells before dilution for platings, the viability of shocked cells reaches that of unshocked control. Time course study of bacterial death after the cold shock, as judged by the subsequent addition of magnesium sulfate $\left(10^{-1} \mathrm{M}\right)$ to the shocked suspension, indicates that the shocked cells immediately after the chilling are in a sublethal state and gradually lose their ability to recover upon prolonged incubation in the chilled buffer. No significant recovery effect by magnesium is observed with the shocked cells incubated in the cold magnesium-free buffer for $120 \mathrm{~min}$.

In another paper (2), we have shown that the spores of Bacillus subtilis are also susceptible to cold shock immediately upon the onset of germination. In accord with the observation on $E$. coli $(1)$, bivalent cation, such as magnesium, calcium, or manganese, in the chilled buffer in which the cells are suspended protects the germinating spores from the cold shock. Although an addition of high concentrations of magnesium sulfate to the cold shocked germinating spores has no appreciable effect on viability, it is found that the incubation of shocked cells at elevated temperature $\left(30^{\circ}\right)$ in the presence of physiological concentration of magnesium sulfate $\left(5 \times 10^{-3} \mathrm{M}\right)$, glucose, and casein acid hydrolyzate causes a rapid recovery in viability. This finding suggests an involvement of an enzymatic reaction(s) for the recovery process.

Another interesting feature of the cold shock is the existence of two critical temperature zones. The rapid chilling of cells by $7-8^{\circ}$ and by $17-20^{\circ}$ always results in an appreciable loss of viability in $E$. coli $(1)$ and in germinating spores of $B$. subtilis (2).

The present paper deals with the recovery from the cold shock with $E$. coli, B. subtilis, and Ps. fluorescens, and the generality of the existence of two critical temperature zones in the cold shock of bacteria. Preliminary accounts for the existence of two critical temperature zones have appeared $(3,4)$.

\section{MATERIALS AND METHODS}

Organism, media and cultural conditions. Escherichia coli K-12 (AMS 6038), Bacillus subtilis (IAM 1026), and Pseudomonas fuorescens (AMS 6101) were used. $E$. coli cells were grown in a nutrient broth medium as described in the previous paper (1). B. subtilis cells were grown with shaking in a test tube containing modified ScHAEFFER's liquid medium as already reported (2). Ps. fluorescens cells were grown in a nutrient broth medium with shaking. One drop of each culture, grown overnight at $30^{\circ}$, was inoculated into a fresh medium and incubated at $30^{\circ}$. Growth was followed by optical densities with a Hitachi photoelectric colorimeter (FPW-4) equipped with a 66 filter $(660 \mathrm{~m} \mu)$.

Preparation of cell suspension. Cells at the exponential phase of growth (optical density 0.28 to 0.35 ) were harvested, washed and resuspended in $10^{-2} \mathrm{M}$ Tris buffer ( $\mathrm{pH} 8.0)$.

Cold shock and viable cell counts. The method for giving cold shock 
was the same as described in previous papers $(1,2)$. A portion $(0.5$ or $1.0 \mathrm{ml})$ of the washed cell suspension at $30^{\circ}$ or $25^{\circ}$ was squirted from a syringe into 49 or 98 volumes of $10^{-2} \mathrm{M}$ Tris buffer ( $\mathrm{pH} 8.0$ ), unless otherwise noted, being stirred at $3^{\circ}$. The mixture was kept stirred for additional 2 to $2.5 \mathrm{~min}$ and then diluted with the same buffer maintained at room temperature. Cells were finally plated on a nutrient broth containing $2 \%$ of agar or the modified Schaeffer's agar medium for E. coli and Ps. fluorescens or B. subtilis, respectively. Colonies appearing on the plates were scored after 14- to 16-hr incubation at $30^{\circ}$. The number of viable cells in each sample was calculated from an average of counts of at least three independent plates.

Measurement of permeability. Measurements were performed according to the method of ALLWOOD and Russell (5). To the cell suspension in deionized water $(10 \mathrm{ml}), 0.5 \mathrm{ml}$ of $5 \times 10^{-3} \mathrm{M}$ sodium 8-anilino-1-naphthalenesulfonate was added. The mixture was incubated for $3 \mathrm{~min}$ at room temperature. Fluorescence at $470 \mathrm{~m} \mu$ was assayed by a Hitachi FPL-2 fluorophotometer with incident light at $405 \mathrm{~m} \mu$. A blank value with the sample containing no dye was subtracted from each reading.

\section{RESULTS}

\section{Recovery from cold shock in presence of magnesium ion}

Like the observation with the cold shocked germinating spores of $B$. subtilis (2), the incubation of cold shocked $E$. coli cells at elevated temperature markedly increased the viability as shown in Table 1 . Although the addition of magnesium, glucose, and casein acid hydrolyzate was needed for the similar recovery of cold shocked $B$. subtilis germinating spores (2), a mere addition of magnesium to the shocked cells of $E$. coli resulted in a significant recovery in viability after a 50 -min incubation at $30^{\circ}$. The optimal concentration of magnesium acetate appears to be around $5 \times 10^{-3} \mathrm{M}$.

Fig. 1 shows the time course of recovery from the cold shock by the addition of $5 \times 10^{-3} \mathrm{M}$ of magnesium acetate. The recovery is much faster at $30^{\circ}$ than at $3^{\circ}$. A similar recovery in viabilities of cold shocked Ps. fluorescens and B. subtilis was also observed. With cold shocked Ps. fluorescens cells, the recovery was observed by the addition of magnesium, and further addition of glucose had no significant effect on the recovery (Fig. 2). With cold shocked B. subtilis cells, which were harvested at the logarithmic phase of growth, incubation in the presence of magnesium had no significant effect on the viability, but on incubation in the presence of magnesium and casein acid hydrolyzate a remarkable increase in viability was observed (Fig. 3). These results are essentially similar to the recovery of cold shocked germinating spores of $B$. subtilis (2).

\section{Time course of bacterial death after cold shock}

Since the incubation of the shocked cells at $30^{\circ}$ in the presence of suitable 
Table 1. Magnesium-mediated recovery of $E$. coli cells from cold shock.

Suspension of washed E. coli cells at $30^{\circ}$ was cold shocked in 98 volumes of Tris buffer at $3^{\circ}$. After $2.5 \mathrm{~min}$, the mixture was divided into 6 portions and magnesium acetate at indicated concentrations was added to each suspension. Incubation of these mixtures was continued for $50 \mathrm{~min}$ at $30^{\circ}$. After this treatment the viability of each sample was determined by the plate method. The initial viable cell count before the cold shock was $2.8 \times 10^{8} / \mathrm{ml}$ and this value was taken as $100 \%$.

\begin{tabular}{|c|c|}
\hline Treatment & $\begin{array}{c}\text { Viability } \\
(\%)\end{array}$ \\
\hline $\begin{array}{l}\text { Cold shocked in Tris buffer } \\
\text { Incubation of shocked cells at } 30^{\circ} \text { in the presence } \\
\text { of } \mathrm{Mg}^{2+} \text { at following concentration (M) }\end{array}$ & 33 \\
\hline none & 46 \\
\hline $1 \times 10^{-3}$ & 83 \\
\hline $5 \times 10^{-3}$ & 89 \\
\hline $1 \times 10^{-2}$ & 79 \\
\hline $2.5 \times 10^{-2}$ & 72 \\
\hline $1 \times 10^{-1}$ & 3 \\
\hline
\end{tabular}

concentrations of magnesium ion resulted in the recovery of viabilities in $E$. coli, the time course of bacterial death after the cold shock was examined. E. coli cells were cold shocked under standard conditions. A portion of the shocked cell suspension at $3^{\circ}$ was withdrawn at certain time intervals, magnesium acetate $\left(5 \times 10^{-3} \mathrm{M}\right)$ was added and incubated at $30^{\circ}$ for $15 \mathrm{~min}$, and then diluted with Tris buffer for the viable cell counting. Its result, shown in Fig. 4, confirmed that the shocked cells gradually lost their ability to recover upon incubation in cold Tris buffer without magnesium ion. This result is in agreement with the data obtained utilizing high concentrations of magnesium for the initiation of recovery in viabilities $(1)$.

\section{Possible requirement of energy source in recovery process}

The observation that the recovery from the cold shock in B. subtilis was stimulated by casein acid hydrolyzate indicates that the process needs an energy source(s) and/or nutrients for some biosynthetic reactions. In order to examine a possible involvement of protein synthesis in the recovery process, the effect of chloramphenicol on the recovery of $E$. coli from the cold shock was examined. Concentration of the antibiotic added was chosen so as to inhibit completely the bacterial growth but without appreciable inhibitory effect on the viability. The data presented in Fig. 5 clearly indicate that chloramphenicol had no effect on the recovery process in E. coli. This result possibly ruled out the involvement of protein synthesis in this process.

To elucidate a possible role of energy sources for the recovery of $E$. coli from cold shock, the effect of 2,4-dinitrophenol (DNP), a well known un- 


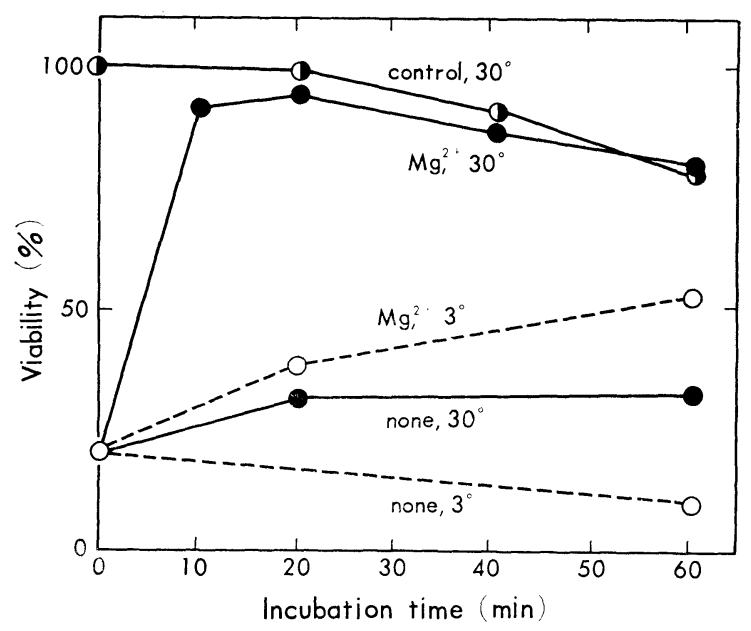

Fig. 1. Time course of magnesium-mediated recovery of cold shocked E. coli.

Suspension of washed E. coli cells at $30^{\circ}$ was cold shocked in 98 volumes of Tris buffer at $3^{\circ}$. After $2.5 \mathrm{~min}$, the mixture was divided into 4 portions and magnesium acetate $\left(5 \times 10^{-3} \mathrm{M}\right.$, final) was added to two portions. Incubation of these mixtures with and without magnesium was started at zero time of this graph and continued either at $30^{\circ}$ or $3^{\circ}$. At time intervals, a portion of each mixture was withdrawn and the viability was determined. Viabilities in per cent were plotted against incubation time. The initial viable cell count before the cold shock was $3.0 \times 10^{8} / \mathrm{ml}$ and this value was taken as $100 \%$.

coupling agent of oxidative phosphorylation, was examined. Again the concentration of DNP was set to give complete growth inhibition but without any significant effect on the viability. The data presented in Figs. $6 \mathrm{a}$ and $6 \mathrm{~b}$ show that the addition of DNP strongly inhibits the recovery which is mediated by magnesium. A similar inhibitory effect of DNP was also observed with B. subtilis (Fig. 3). If these observations truly represent an energy-requiring nature of the recovery process from the cold shock, it should be possible to overcome the inhibitory effect of DNP by a suitable addition of energy sources. In fact, when ATP or NAD was added to the reaction mixture which contained magnesium and DNP, the inhibitory effect was partly released (Fig. 6a). NAD was more effective than ATP. The addition of NAD in the absence of magnesium, however, had no significant effect on the viability (Fig. 6a). Furthermore, the addition of ATP plus nicotinamide to the reaction mixture, which contained DNP and magnesium, stimulated the recovery more effectively than the independent addition of ATP (Fig. $6 \mathrm{~b}$ ). ATP plus nicotinamide was almost 


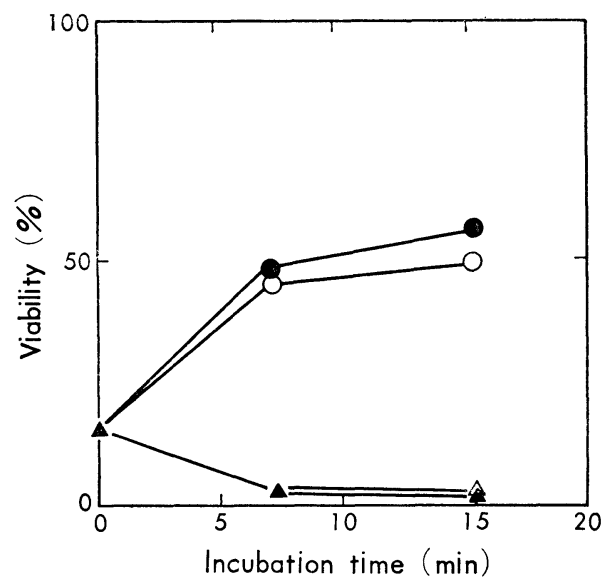

Fig. 2. Recovery of Pseudomonas fluorescens from cold shock.

Suspension of washed Ps. fluorescens cells at $30^{\circ}$ was cold shocked in 49 volumes of Tris buffer. After $20 \mathrm{sec}$, the shocked suspension was divided into portions. Each portion was added with the indicated additive and incubated at $30^{\circ}$. Incubation was started at zero time. At time intervals, viabilities were determined and plotted against incubation time. Initial viable cell count before the cold shock was $2.6 \times 10^{8} / \mathrm{ml}$. Where indicated, $5 \times 10^{-3} \mathrm{M}$ of magnesium acetate and $5.6 \times 10^{-3} \mathrm{M}$ of glucose were added at final concentrations.

- $\mathrm{O}-\mathrm{Mg}^{2+}, \quad-0-\mathrm{Mg}^{2+}+$ glucose

$-\Delta-$ glucose, $-\Delta-$ none

as effective as NAD when Figs. $6 \mathrm{a}$ and $6 \mathrm{~b}$ are compared. Although NADP had some stimulatory effect, nicotinamide had no appreciable stimulatory effect in the presence of magnesium and DNP (Fig. 6b).

Since the recovery from the cold shock mediated by magnesium ion is a very rapid process at $30^{\circ}$, as shown in Fig. 1, the stimulatory effect of NAD for the recovery in the absence of DNP was examined at $3^{\circ}$ in order to decrease the rate of recovery. As shown in Fig. 7, the addition of magnesium had some effect on the recovery at $3^{\circ}$, but further addition of NAD definitely stimulated the rate of recovery. These data strongly suggest that NAD is involved in the recovery process from the cold shock probably as an energy source.

Permeability change induced by cold shock

$E$. coli is generally impermeable to ionized or charged molecules, with the exception of those for which it possesses specific transport systems (6). 


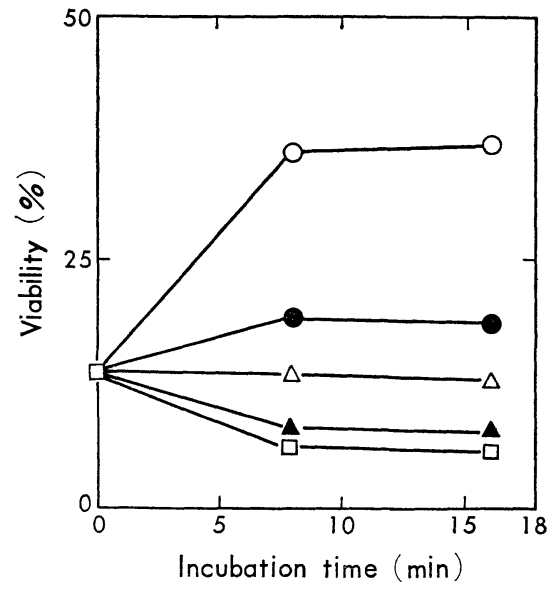

Fig 3. Recovery of Bacillus subtilis from cold shock.

Suspension of washed B. subtilis cells at $30^{\circ}$ was cold shocked in 49 volumes of Tris buffer at $3^{\circ}$. After $2 \mathrm{~min}$, the mixture was divided into 5 portions. Indicated additions were made to each vessel and immediately thereafter incubated at $30^{\circ}$. The incubation started at zero time. A portion of each mixture was withdrawn at time intervals and the viability was determined. The final concentrations of $\mathrm{MgSO}_{4}$, casein acid hydrolyzate, and 2, 4-dinitrophenol (DNP) were $5 \times 10^{-3} \mathrm{M}$, $0.15 \%$, and $5.4 \times 10^{-4} \mathrm{M}$, respectively. Initial viable cell count before the cold shock was $3.0 \times 10^{8} / \mathrm{ml}$ and this value was taken as $100 \%$.

Following symbols were used:

- $\mathrm{O}-\mathrm{Mg}^{2+}+$ casein acid hydrolyzate

- - $\mathrm{Mg}^{2+}+$ casein acid hydrolyzate $+\mathrm{DNP}$

$-\Delta-$ casein acid hydrolyzate

$-\Delta-\mathrm{Mg}^{2+}$

$-\square-$ none

NADIor ATP is considered unable to enter into cells because of this permeability barrier. Thus, the stimulatory effect of NAD or ATP shown above conflicts with this consideration if the permeability barrier is unaffected by the cold shock. Although an increase in permeability of cold shocked bacteria has been reported by several workers $(7,8)$, the permeability change after the present cold shock treatment was examined with the aid of 8anilino-1-naphthalenesulfonate, a dye which fluoresces when combined with protein. As shown in Table 2, unshocked control cells emitted feeble fluorescence but the heat-treated cells emitted 14 times as much fluorescence as the control cells indicating that the permeability barrier is destroyed by the 


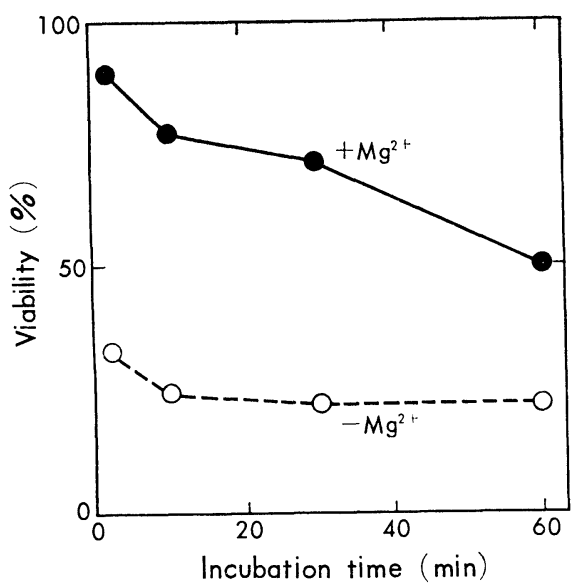

Fig. 4. Time course of bacterial death after cold shock of E. coli.

Suspension of washed $E$. coli cells was cold shocked in 49 volumes of Tris buffer at zero time. The shocked cells were incubated at $3^{\circ}$. At time intervals, a portion of the cell suspension was withdrawn and was divided into two parts. Magnesium acetate at the final concentration of $5 \times 10^{-3} \mathrm{M}$ was added to one portion. Both suspensions were incubated at $30^{\circ}$ for $15 \mathrm{~min}$ and then diluted with Tris buffer. Viabilities were determined and plotted against incubation time. Initial viable cell count before the cold shock was $4 \times 10^{8} / \mathrm{ml}$.

- with $\mathrm{Mg}^{2+}$, -..- without $\mathrm{Mg}^{2+}$

heat treatment. On the other hand, the cold shocked cells emitted half as much fluorescence as heat treated cells, showing that the dye can penetrate the cells in contrast to the unshocked cells. Thus, the increase in permeability of shocked cells was confirmed. This result suggests that NAD or ATP can possibly enter into the shocked cells because of this increase in permeability.

Two critical temperature zones in cold shock of B. subtilis and Ps. fluorescens

In the preceding paper, we have shown the presence of two critical temperature zones in the cold shock of $E$. coli (1). A similar type of work was performed with $B$. subtilis and Ps. fuorescens to examine the generality of this phenomenon. As shown in Fig. 8, two critical temperature zones appeared in both cases. When the initial temperature of the cell suspension was lowered by $5^{\circ}$, the critical zones moved to lower temperature sides approximately by $3-5^{\circ}$. Therefore, it is apparent that the magnitude of chilling, not the rapid passage of a definite temperature zone, is an important con- 


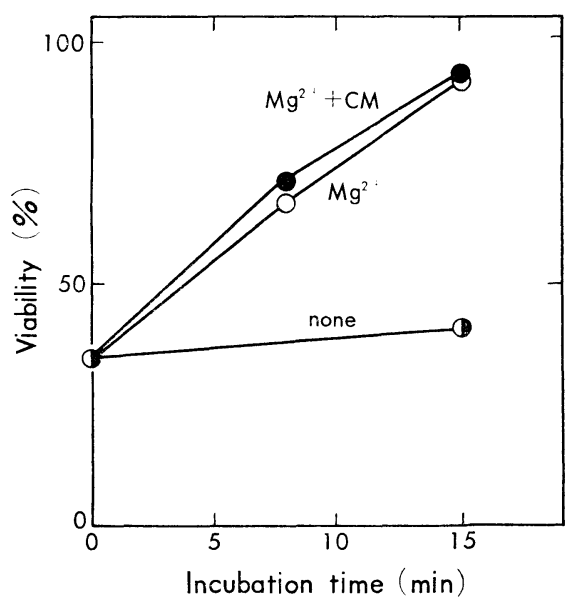

Fig. 5. Effect of chloramphenicol on recovery of E. coli from cold shock.

Suspension of washed $E$. coli cells was cold shocked in 98 volumes of Tris buffer. After $2.5 \mathrm{~min}$, the suspension was divided into several portions. To each portion was added the indicated additive(s) and incubated at $30^{\circ}$. Incubation was started at zero time. At time intervals, viabilities were determined and plotted against incubation time. Initial viable cell count before the cold shock was $4.4 \times 10^{8} / \mathrm{ml}$. Where indicated, $5 \times 10^{-3} \mathrm{M}$ of magnesium acetate and $10 \mu \mathrm{g} / \mathrm{ml}$ of chloramphenicol (CM) were added at final concentrations.

dition for giving the cold shock effect. The results obtained with both strains are very similar to those observed with $E$. coli and germinating spores of $B$. subtilis (2). Thus, the generality of the existence of two critical temperature zones in the cold shock of various bacteria is confirmed.

\section{DISCUSSION}

The present experiment clearly demonstrated that the incubation of the cold shocked cells at $30^{\circ}$ with physiological concentration of magnesium ion resulted in a rapid recovery in viability. The reported effect of unusually high concentration of magnesium on the cold shocked $E$. coli cells (1) is attributable to the recovery occurring during plating procedures. Earlier, the shocked cells were exposed to high concentrations of magnesium for a short period, and then diluted with Tris buffer for the viable cell counting (1). Since this recovery is a rapid process, it should have occurred in Tris buffer maintained at room temperature with a suitable concentration of 


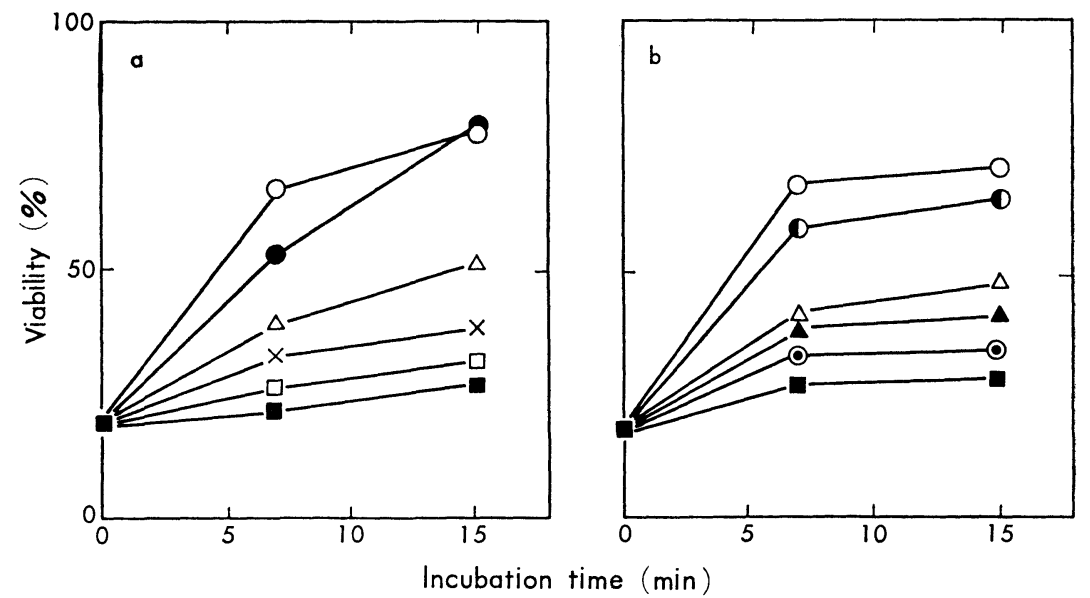

Fig. 6. Effect of various agents on recovery of $E$. coli from cold shock.

Suspension of washed $E$. coli cells was cold shocked in 98 volumes of Tris buffer at $3^{\circ}$. After $3 \mathrm{~min}$, the shocked suspension was divided into portions. Each portion was added the indicated additive and incubated at $30^{\circ}$. Incubation was started at zero time. At time intervals, viabilities were determined and plotted against incubation time. Initial viable cell counts for expts. $a$ and $b$ before the cold shock were $3.0 \times 10^{8}$ and $3.6 \times 10^{8} / \mathrm{ml}$, respectively. Where indicated, $5 \times 10^{-3} \mathrm{M}$ of magnesium acetate, $5.4 \times 10^{-4} \mathrm{M}$ of 2, 4-dinitrophenol (DNP), $1.5 \times 10^{-3} \mathrm{M}$ of $\mathrm{NAD}, 1.7 \times 10^{-3} \mathrm{M}$ of ATP, $1.4 \times 10^{-3} \mathrm{M} \mathrm{NADP}$, and $4 \times 10^{-3} \mathrm{M}$ of nicotinamide were added at final concentrations.

Fig. 6a. $-\mathrm{O}-\mathrm{Mg}^{2+}$

$$
\begin{aligned}
& -\square-\mathrm{Mg}^{2+}+\mathrm{DNP}+\mathrm{NAD} \\
& -\triangle-\mathrm{Mg}^{2+}+\mathrm{DNP}+\mathrm{ATP} \\
& -\square-\mathrm{Mg}^{2+}+\mathrm{DNP} \\
& -\times-\mathrm{NAD} \\
& -\square-\text { no addition }
\end{aligned}
$$

For Fig. 6b. Same as above except for

$$
\begin{aligned}
& -\boldsymbol{O} \mathrm{Mg}^{2+}+\mathrm{DNP}+\mathrm{ATP}+\text { nicotinamide } \\
& -\mathbf{A}-\mathrm{Mg}^{2+}+\mathrm{DNP}+\mathrm{NADP} \\
& -\odot-\mathrm{Mg}^{2+}+\mathrm{DNP}+\text { nicotinamide }
\end{aligned}
$$

magnesium ion.

The finding that the recovery of cold shocked $E$. coli cells mediated by magnesium is much faster at $30^{\circ}$ than at $3^{\circ}$, and that recovery of cold shocked $B$. subtilis cells needs casein acid hydrolyzate in addition to magnesium, suggest that the recovery process involves an enzymic reaction(s). Although chloramphenicol has no effect on magnesium-mediated recovery of $E$. coli, DNP strongly inhibits the recovery. Furthermore, the addition of NAD stimulates the recovery even in the presence of DNP. These results further 


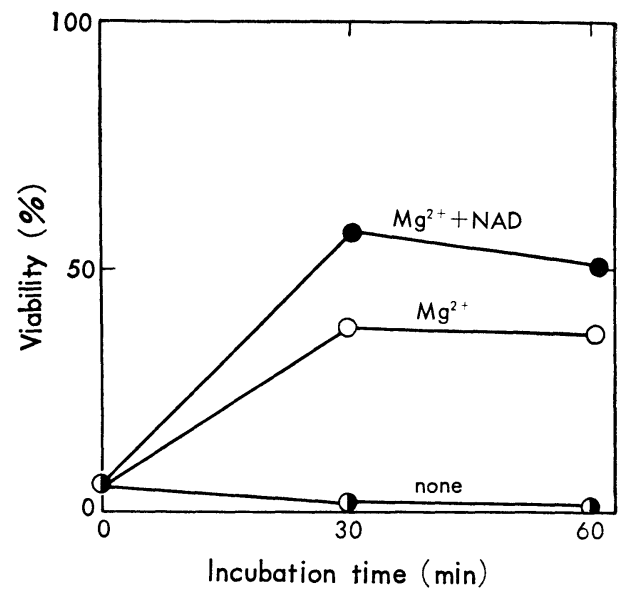

Fig. 7. Effect of NAD on recovery of $E$. coli from cold shock.

Suspension of washed $E$. coli cells was cold shocked in 98 volumes of Tris buffer. After $2 \mathrm{~min}$, the suspension was divided into several portions. Each portion was added the indicated additive and incubated at $3^{\circ}$. Incubation was started at zero time. At time intervals, viabilities were determined and plotted against incubation time. Initial viable cell count before the cold shock was $4.2 \times 10^{8} / \mathrm{ml}$. Where indicated, $5 \times 10^{-3} \mathrm{M}$ of magnesium acetate and $1.5 \times 10^{-3} \mathrm{M}$ of $\mathrm{NAD}$ were added at final concentrations.

Table 2. Increase in permeability of cold shocked $E$. coli as determined by absorption of 8-anilino-1-naphthalenesulfonate.

A portion of the washed $E$. coli cell suspension $\left(7.0 \times 10^{9}\right.$ viable cells $\left./ \mathrm{ml}\right)$ was cold shocked in 49 volumes of Tris buffer at $3^{\prime}$. After $3 \mathrm{~min}$, a small portion of the shocked suspension was withdrawn and the viability determined. The remaining shocked cells and unshocked cells were spun down, washed once with deionized water, and finally suspended in deionized water so as to contain the same number of cells. A portion of unshocked cell suspension was diluted and heat treated at $70^{\circ}$ for $5 \mathrm{~min}$. To each cell suspension, sodium 8-anilino-1-naphthalenesulfonate was added, and fluorescence at $470 \mathrm{~m} \mu$ was assayed. The value for heat-treated cells was corrected for the dilution.

\begin{tabular}{l|c|r}
\hline \multicolumn{1}{c|}{ Sample } & $\begin{array}{c}\text { Relative strength of fluorescence } \\
\text { (meter reading in divisions) }\end{array}$ & $\begin{array}{c}\text { Viability } \\
(\%)\end{array}$ \\
\hline Unshocked control cells & 1.0 & 100 \\
Cold shocked cells & 7.0 & 30 \\
Heat-treated cells & 13.8 & - \\
\hline
\end{tabular}




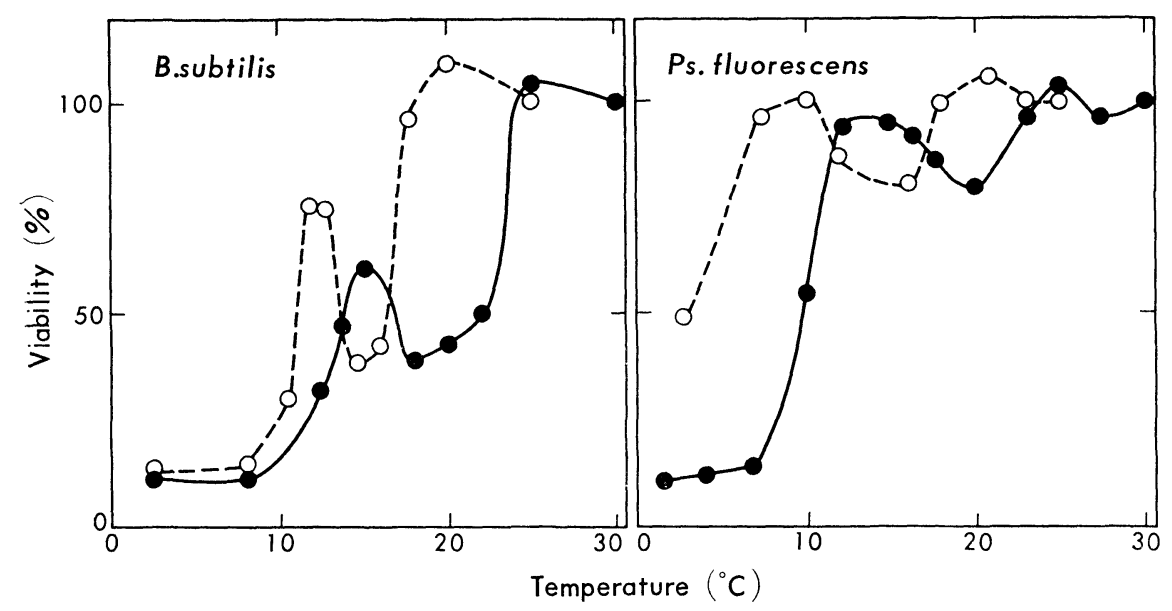

Fig. 8. Critical temperature zones in cold shock of B. subtilis and Ps. fluorescens.

Suspensions of washed cells of B. subtilis and Ps. fuorescens were obtained from the exponentially growing cultures at $30^{\circ}$. Each suspension was divided into two portions. One was kept at $30^{\circ}$ and the other at $25^{\circ}$. A portion of each suspension was cold shocked in 49 volumes of Tris buffer maintained at the temperature indicated on the abscissa. Viabilities were determined and plotted against temperatures at which cold shock was given. The initial viable cell counts before the cold shock were as follows. B. subtilis: Shock from $30^{\circ}, 4.8 \times 10^{7} / \mathrm{ml}$ and shock from $25^{\circ}, 4.2 \times 10^{7} / \mathrm{ml}$. Ps. fluorescens: Shock from $30^{\circ}, 4.2 \times 10^{8} / \mathrm{ml}$ and shock from $25^{\circ}, 3.6 \times 10^{8} / \mathrm{ml}$.

- Cold shock from $30^{\circ} \quad \bigcirc \ldots \bigcirc$ Cold shock from $25^{\circ}$

substantiate above hypothesis.

Since NADP has little effect on the recovery, but ATP plus nicotinamide is as effective as NAD, NAD appears to be a specific factor required for the recovery process. The inhibition of the magnesium-mediated recovery by DNP and the stimulation of the recovery by NAD under such conditions suggest the possible role of NAD as an energy source for the recovery process. Although a number of dehydrogenases exist which specifically require $\mathrm{NAD}$ as an electron acceptor, only a few enzymes have been known that require $\mathrm{NAD}$ as an energy source (9-11). Among these enzymes, DNA ligase, which is present in $E$. coli cells and catalyzes the joining of singlestranded breaks in double stranded DNA (10-13), is worth noting, since the requirements for NAD and metallic ions are very similar to the recovery process observed in this experiment. The possible involvement of DNA ligase reaction in the recovery from the cold shock will be reported in a subsequent paper.

Since the incubation of shocked cells with magnesium ion resulted in the recovery of viability, no appreciable loss in viability was noted when 
the cold shock was performed in Tris buffer containing magnesium ion (1), and permeability of the cells increased after the cold shock, it appears that the shocked cells lose their viability as a result of leakage of intracellular bivalent cations, at least in $E$. coli and Ps. fluorescens. Leakage of cellular materials in addition to bivalent ions appears to be responsible for the loss of viability in vegetative and germinating spores of $B$. subtilis, since the supplement of casein acid hydrolyzate plus magnesium was needed for recovery from the cold shock. Furthermore, an involvement of another mechanism for the death of the cells is evident, since the ability of $E$. coli cells to recover from cold shock gradually decreased on incubation in cold magnesium-free Tris buffer. Therefore, further studies are needed in order to draw a complete picture concerning the mechanism of bacterial death upon cold shock.

The authors are grateful to Dr. Kazuo Izaki of this laboratory for his valuable discussions.

\section{REFERENCES}

1) M. Sato and H. Takahashi, J. Gen. Appl. Microbiol., 14, 413 (1968).

2) M. Sato, M. Suzuki and H. Takahashi, Agr. Biol. Chem., 32, 1270 (1968).

3) M. Sato and H. TAkahashi, Agr. Biol. Chem., 31, 1100 (1967).

4) M. Sato and H. Takahashi, Agr. Biol. Chem., 32, 259 (1968).

5) M.C. Allwood and A.D. Russell, Appl. Microbiol., 15, 1266 (1967).

6) L. Leive, Proc. Natl. Acad. Sci. U.S., 53, 745 (1965).

7) R.E. Strange and J.R. Postgate, J. Gen. Microbiol., 36, 393 (1964).

8) J.R. Smeaton and W.H. Elliott, Biochem. Biophys. Res. Commun., 26, 75 (1967).

9) L.J. Zatman, N.O. Kaplan and S.P. Colowick, J. Biol. Chem., 200, 197 (1953).

10) S.B. Zimmerman, J.W. Little, C.K. Oshinsky and M. Gellert, Proc. Natl. Acad. Sci. U.S., 57, 1841 (1967).

11) T. Sugimura, S. Fujimura, S. Hasegawa and Y. Kawamura, Biochim. Biophys. Acta, 138, 438 (1967).

12) B.M. Olivera and I.R. Lehman, Proc. Natl. Acad. Sci. U.S., 57, 1426 (1967).

13) J.W. Little, S.B. Zimmerman, C.K. Oshinsky and M. Gellert, Proc. Natl. Acad. Sci. U.S., 58, 2004 (1967). 